\title{
DIVERSIDAD SOCIOCULTURAL, EQUIDAD E INTERCULTURALIDAD EN LAS CREENCIAS DOCENTES EN UNIVERSIDADES PRIVADAS CON PROYECTO DE INCLUSIÓN
}

Ana María Contreras Duarte ${ }^{1}$

1 Chilena. Trabajadora Social, Magíster en Educación y Doctora en Ciencias de la Educación, Mención Educación intercultural, Universidad de Santiago de Chile. Académica Escuela de Trabajo Social Universidad Católica Silva Henríquez, UCSH.

acontrer@ucsh.cl 


\section{RESUMEN}

El capítulo aborda los problemas de equidad e inclusión en la educación superior en Chile, desde una perspectiva que se sitúa más próxima al campo de la sociología de la educación. De allí que la perspectiva teórica que sirve de marco orientador del estudio, se plantea la posibilidad de comprensión de los fenómenos sociales desde las creencias y acciones de los sujetos. También se asume que el logro de la justicia en una sociedad determinada y en la educación en particular, trasciende a la distribución equitativa de recursos y requiere que los actores educativos se reconozcan mutuamente, como lo plantean los teóricos del reconocimiento (Honneth, 2010). Analizar las creencias docentes y los proyectos institucionales de universidades con proyecto de inclusión, desde la perspectiva de las posibilidades de una educación superior inclusiva e intercultural, permite reconocer espacios a fortalecer para el logro de la justicia educativa en este nivel de enseñanza y discutir las posibilidades de legitimación y apropiación de las metas de equidad e inclusión de la diversidad cultural en educación superior.

\section{INTRODUCCIÓN}

El sistema de educación superior se despliega en un contexto de grandes transformaciones sociales, económicas y culturales que se traducen en la presencia de diversidad; no solo estudiantil, sino también académica e institucional, que requieren ser exploradas para responder a las metas de equidad que se hacen a este nivel de enseñanza. Los problemas de equidad e inclusión de la diversidad social, han sido abordados tradicionalmente desde un enfoque de justicia social que pretende resolver las brechas de desigualdad a partir del discurso de la igualdad de oportunidades. Las distintas teorías del reconocimiento, han puesto el acento en la crítica a la perspectiva fundamentalmen- 
te distributiva de las teorías de justicia, partiendo del supuesto que el logro de esta en una sociedad determinada, trasciende a la distribución equitativa de recursos y requiere que los sujetos además se reconozcan mutuamente.

En la perspectiva de aportar al análisis de la justicia educativa en la educación superior, se propone en este estudio, identificar en las creencias docentes de universidades denominadas "inclusivas", concepciones respecto de la equidad en la educación superior y la inclusión social de estudiantes no tradicionales y analizarlas en la perspectiva de la educación inclusiva de carácter intercultural.

Se le adjudica a la educación en este nivel de enseñanza, no sin cuestionamientos ${ }^{2}$, un rol relevante como herramienta para enfrentar problemas de desigualdad social y promover mejores condiciones para el desarrollo de los pueblos. En esta dirección, Artavia y Cascante (2009) señalan que

La educación ha sido, en el transcurso de este siglo, $-\mathrm{y}$, posiblemente lo seguirá siendo en el futuro- uno de los instrumentos más importantes con los que han contado las sociedades modernas para luchar contra las desigualdades sociales, para hacer frente a los fenómenos y a los procesos de segregación y exclusión social, para establecer, ampliar y profundizar los valores cívicos y democráticos, para impulsar el desarrollo económico y cultural y para promover el desarrollo personal y el mejoramiento de la calidad de vida de todos sus miembros. (Artavia \& Cascante, 2009 p.54)

2 La teoría del capital humano atribuye diferencias de ingresos entre los individuos a partir de la inversión en educación. Una postura contraria pone su acento en la función de reproducción social de la educación (Espinoza y González, 2010). La posición oficial del Banco Mundial, hasta hace algunos años, ponía en duda la efectividad de la inversión en la educación superior en los países en desarrollo, especialmente de la pública (Bonal, 2002). 
No obstante, las instituciones educativas deben enfrentar una sociedad en transformación en la que se hace difícil concretar estas metas. Se observan cambios importantes, impulsados por el capitalismo global que han impactado no solo los modos de vida de las personas y sus relaciones, sino también las formas de organización de las diversas funciones sociales entre las que se incluye la educación, contribuyendo a la generación de nuevas desigualdades.

Un elemento fundamental en el logro de la equidad y calidad en la educación superior, tiene relación con la capacidad del sistema y las instituciones de acoger la diversidad sociocultural de los estudiantes que concurren en este nivel de enseñanza y que se vincula, de un modo importante, con las opciones de carácter curricular y docente en el proceso de formación. Diversos autores (Giménez \& Malgesini, 2000; Ramírez, 2006) reconocen la necesidad de incorporar a la educación programas y estrategias que recojan la diversidad cultural ante el incremento creciente de la inmigración desde países de otros continentes al europeo. En Chile, Díaz (2009) advierte sobre la situación mapuche y la exigencia del respeto a sus derechos culturales, los que deben ser considerados en la educación universitaria junto con otras desventajas generadas por su ubicación geográfica, la pobreza y escaso capital cultural para enfrentar una educación hegemónica (Díaz, 2009). Para la autora, es necesario generar condiciones para la concreción del derecho a una educación de calidad, pertinente, contextualizada, sin discriminación en educación superior $\mathrm{y}$, específicamente, revisar la labor de las universidades en su capacidad de dar cabida a la diversidad, generando espacios para la interculturalidad y la promoción de una educación respetuosa de todos (Díaz, 2009). 
Estos planteamientos respecto de la población indígena y la necesidad de una educación de calidad, pertinente y sin discriminación, son válidos también para analizar la problemática de la interculturalidad en la educación superior desde la perspectiva de la diversidad social y económica de los estudiantes, especialmente con la incorporación de otros grupos sociales distintos a los que accedían tradicionalmente. La tendencia en la literatura especializada es identificar educación intercultural con el derecho a la educación en la diversidad de migrantes, como en el caso europeo o de los pueblos originarios en América Latina, obviando en esta forma de abordaje, la situación de menoscabo que viven otros grupos sociales al interior del sistema educativo. Es necesario ampliar el enfoque de diversidad que subyace a las propuestas de inclusión social en la educación superior hacia otros grupos, de manera que la educación a nivel universitario pueda cumplir con las demandas que los procesos de expansión y masificación vienen a realizar. La presencia de grupos de jóvenes provenientes de sectores que vivencian pobreza, adultos jóvenes trabajadores, estudiantes provenientes de familias sin tradición universitaria, discapacitados físicos, es aún insuficiente y los sistemas no están preparados para su manutención. El enfoque de educación intercultural, aun cuando es todavía una perspectiva en construcción, propone un particular modo de abordaje de esta tensión entre metas de equidad y calidad en contextos de diversidad sociocultural. Para la educación intercultural, un pilar fundamental es la recuperación del sujeto culturalmente diverso y la legitimidad de su presencia en este espacio habitado históricamente por la élite.

La probabilidad de estudios postsecundarios ha mejorado a partir de los años noventa en todos los segmentos sociales, llegando casi a triplicarse para el caso de los dos quintiles más 
pobres de la población. Este hecho, que ha sido bien evaluado por los organismos internacionales (OCDE, 2009), esconde una nueva problemática, y es que también en este segmento de población se encuentran quienes más abandonan la enseñanza en este nivel. La investigación sobre deserción universitaria sugiere que los estudiantes chilenos que dejan el sistema terciario, lo hacen motivados por causas económicas, socioculturales y motivacionales (Canales \& De los Ríos, 2007). Los grupos que tradicionalmente no ingresaban a la universidad, además de estar menos representados, son responsabilizados del fracaso y descalificados a partir de la ausencia de aquellas características que "todo universitario debe poseer". Para Tedesco, se trata de nuevas desigualdades de carácter intra categorial "más difíciles de aceptar porque ponen en crisis la representación que cada uno tiene de sí mismo" (2000, p.567). Estas nuevas desigualdades generarían, muchas veces, una perturbación sobre la autopercepción de la identidad del sujeto. Hay acuerdo en la literatura especializada (Schmelkes, 2006; UNESCO, 2009) en que la equidad educativa debe ser un propósito en la educación superior, traducida no solo en un aumento de la representación de los distintos sectores que conforman la sociedad, sino una efectiva inclusión social, lo que obliga a las instituciones a revisar expectativas y pertinencia de los contenidos curriculares y modelos pedagógicos con los que trabajan (Díaz y Romero, 2010).

\section{MARCO TEÓRICO}

En este punto se desarrollan algunos planteamientos que es posible identificar en la literatura respecto de aquello que se entiende por interculturalidad, educación intercultural, creencias docentes y reconocimiento. Lo anterior permitirá comprender el campo de la educación en este nivel e identificar algunas categorías para el análisis del objeto de estudio de modo que, a 
través de este proceso analítico de las creencias docentes y los discursos institucionales sobre el sistema educativo y la diversidad sociocultural de los sujetos, se identifiquen las posibilidades para el logro de la equidad y el diálogo intercultural en la educación superior. No se trata de enmarcar el estudio en un modelo teórico en particular, sino de indagar en la bibliografía pertinente a fin de aprovechar la riqueza del discurso que se irá construyendo. No obstante los resultados se examinan en la perspectiva de comprender las nociones de equidad, inclusión y diversidad presentes en los discursos docentes desde la perspectiva de la teoría del reconocimiento y los elementos que esta ofrece para identificar condiciones y esferas en que este es posible para el logro de mayor justicia social.

\section{INTERCULTURALIDAD, MULTICULTURALIDAD Y PLURALISMO}

La preocupación por la interculturalidad y su impacto en la educación surge en el ámbito académico en la década del ochenta. Nuevos movimientos sociales confluyen en términos programáticos bajo el paraguas del multiculturalismo, reivindicando el valor de la diferencia y la lucha por la pluralización de las sociedades que acogen a grupos que defienden derechos étnicos y culturales (Dietz, 2012). Para Giménez \& Malgesini (2000), a diferencia de otros modelos, el pluralismo cultural valora positivamente la diversidad sociocultural y toma como punto de partida la necesidad de todo grupo de preservar su cultura o identidad propia. El pluralismo así entendido permite verificar la existencia en un mismo sistema social de una diversidad de intereses, valores, posiciones y comportamientos de las personas que interactúan en contextos comunicativos diversos, partiendo de la base que los procesos culturales son dinámicos e interdependientes. "El pluralismo cultural es aquella ideología o 
modelo de organización social que afirma la posibilidad de convivir armoniosamente en sociedades grupos o comunidades étnica, cultural, religiosa o lingüísticamente diferentes" (Giménez \& Malgesini, 2000, p.323). Esta perspectiva concibe las diversas culturas y la relación de interdependencia entre ellas como procesos dinámicos de intercambio, valiosos para el desarrollo de la humanidad. Por su parte, la multiculturalidad, otra forma de aproximación a la diversidad cultural, es entendida como un enfoque que promueve la acción de reconocimiento pleno del carácter multilingüe, multiétnico y pluricultural de un país o nación. Salazar (2009) señala:

El multiculturalismo se apoya en valores como la equidad y la justicia, la igualdad con derecho a la diferencia étnica y cultural, y se manifiesta a través del ejercicio de reconocimiento, respeto y promoción de la identidad cultural y lingüística. (p.15)

Al analizar las contribuciones que la perspectiva multicultural ha realizado en el ámbito del reconocimiento y el derecho a la diferencia de grupos sociales considerados minoritarios, el autor señala que ha aportado a la promoción de un mayor respeto de las culturas y los pueblos; al impulso a reformas del sistema educativo; la lucha contra el racismo y la discriminación; la regionalización cultural del currículum educacional, fortaleciendo a la vez un currículum básico nacional, de manera que propicie la unidad en la diversidad (Salazar, 2009). No obstante, también se le critica señalando que solo haría referencia a un hecho de facto, que no visibiliza la dinámica de la interrelación entre los grupos o al interior de uno de ellos. La aparición del término interculturalidad parece motivada entonces, por las carencias de los conceptos de multiculturalidad para reflejar la dinámica social y para formular el objetivo de nuevas síntesis socioculturales (Giménez, 2000). De este modo la perspectiva intercultural surge como un 
paradigma más complejo ya que tiene en cuenta no solo las diferencias entre personas y grupos sino también las convergencias entre ellos, los vínculos que unen, la aceptación de los derechos humanos, los valores compartidos, entre otros aspectos. Esta forma de enunciar la presencia de diversidad afirmaría de forma expresa la realidad del encuentro caracterizada por el diálogo, la reciprocidad y la interdependencia, y expresaría la necesidad de pensar los procesos educativos en términos dinámicos, de interacción, intercambio y reconocimiento mutuo entre sujetos con diferentes referentes culturales.

Para Tarrow (1992), los paradigmas con los cuales los Estados nacionales pluriculturales y multilingües han abordado el fenómeno son: asimilación, aceptación e interculturación. El primero de ellos parte de una concepción mono-cultural de la sociedad que desconoce el pluralismo y la igualdad entre las personas buscando la uniformidad cultural y lingüística. En el paradigma de aceptación, aún se niega la igualdad entre los grupos, pero fomenta programas de compensación para atender necesidades de las minorías e integrarlas a la sociedad dominante. Finalmente desde la interculturación, el objetivo es el diálogo entre culturas poniendo al centro los conceptos de interacción, interdependencia, intercambio y reciprocidad (Tarrow, 1992). Giménez (2006) establece diferencias fácticas y normativas entre las perspectivas multi e interculturales, útiles para realizar distinciones al mirar la literatura sobre el tema y comprender distintas formas de aproximación al fenómeno representados en el esquema de la siguiente página.

La propuesta intercultural da un paso más allá de la constatación de situaciones de diferencia y desigualdad enfatizando la interdependencia y la reciprocidad de los intercambios. Es fre- 
cuente ver en la literatura que la idea de interculturalidad está asociada con la integración de minorías migratorias o con las luchas de organizaciones indígenas o étnicas por el reconocimiento de sus diferencias y la valorización de sus cosmovisiones en distintos ámbitos de la vida social y política.

Multi e interculturalidad

\begin{tabular}{|l|l|l|}
\hline \multicolumn{1}{|c|}{ Nivel } & \multicolumn{1}{|c|}{ Multi-cultural } & \multicolumn{1}{|c|}{ Intercultural } \\
\hline Descriptivo/factual & $\begin{array}{l}\text { Coexistencia/ presencia de } \\
\text { diversidad cultural, lingüísti- } \\
\text { ca, religiosa }\end{array}$ & $\begin{array}{l}\text { Relaciones inter-étnicas, } \\
\text { interculturales, } \\
\text { interreligiosas }\end{array}$ \\
\hline Prescriptivo/normativo & $\begin{array}{l}\text { Reconocimiento de la dife- } \\
\text { rencia } \\
\text { (Principios de igualdad y di- } \\
\text { ferencia) }\end{array}$ & $\begin{array}{l}\text { Convivencia en la diversidad } \\
\text { (Principios de igualdad dife- } \\
\text { rencia e interacción positiva) }\end{array}$ \\
\hline
\end{tabular}

Fuente: Giménez (2006)

Para Mato (2007), la idea de interculturalidad es una categoría meramente descriptiva, que alude a la existencia de relaciones "entre" culturas, o entre actores sociales o individuos culturalmente diversos entre sí, aun cuando también persisten posiciones que la consideran un valor. Para el autor, en la educación superior, la idea de interculturalidad está investida de atributos positivos, como ideario u orientación ético-política y orienta investigaciones, políticas y programas. En la perspectiva de Sartorello (2009) es posible identificar al menos dos polos de interpretación de la interculturalidad: uno funcional al Estado-nación neoliberal, que concibe las políticas interculturales como mecanismos de carácter asistencial y de integración subordinada de grupos excluidos, cuyo reconocimiento asegura gobernabilidad, pero no necesariamente mayor equidad social. El otro polo, sería un enfoque crítico al sistema político y económico neoliberal, que considera la interculturalidad como un derecho y un medio a través del cual las culturas minoritarias y en situación de subalternidad, aseguran su preservación. La primera posi- 
ción estaría representada por los organismos internacionales del capitalismo global y por algunos estados, que se apropian del ideal democratizador del proyecto intercultural a través de su burocratización. La segunda, sostenida por los pueblos indígenas, que desde una visión altermundista lucha por la convivencia en una sociedad más equitativa y justa, con derecho a su diferencia (Sartorello, 2009). Son muchas las concepciones de interculturalidad que están a la base de proyectos, políticas y propuestas de actores sociales igualmente diversos. Por ello es necesario avanzar en la investigación para develar las nociones que están organizando el actuar teórico y político de los actores que participan en procesos de carácter intercultural. Para Mato (2007) es vital comprender las diversas ideas de interculturalidad, sus diferencias y convergencias, sus significados en contextos de producción, sus modos de comunicación y transferencia. Importa conocer procesos de apropiación, resignificación y aplicación de este constructo, además del lugar que estas experiencias ocupan en las universidades y en la producción de conocimientos.

El discurso multiculturalista y su posterior desarrollo hacia la interculturalidad ha sido objeto de preocupación de la academia y de políticas públicas fundamentalmente en el ámbito de la educación. Para Dietz (2012) se da la confluencia programática de movimientos sociales que en la década del sesenta, levantan demandas situadas desde la perspectiva de la constitución desigual de la sociedad. La interculturalidad va adquiriendo notoriedad constituyendo en la actualidad un fenómeno complejo desde el punto de vista no solo académico sino social y político. Emerge de este modo, como una apuesta ético-política de resistencia a la modernidad occidentalizadora y de radicalización de la democracia. Desde la resistencia busca la valorización 
de identidades despreciadas sin segregar y como proyecto se orienta hacia la paz positiva (Tubino, 2005).

La relación entre educación y movimiento multicultural instala estratégicamente sus preocupaciones en la academia y la escuela, logrando por una parte la institucionalización de la problemática y mayores posibilidades de acción, pero por otra debilita el carácter contra-hegemónico de sus reivindicaciones (Dietz, 2007). Es así como, junto con el debate universitario y los estudios étnicos y culturales, se va originando una alianza del multiculturalismo con la escuela y la consiguiente pedagogización del discurso y las prácticas.

\section{LA EDUCACIÓN INTERCULTURAL}

Lo planteado en el punto anterior permite observar cómo evoluciona el discurso multicultural, desde un movimiento reivindicativo a su institucionalización, a través de la política educativa como modo de gestionar la diversidad educativa en el aula. Examinando los objetivos de la educación intercultural Walsh (2005) establece que estos deben orientarse hacia cuatro aspectos fundamentales; el primero de ellos es: "fortalecer y legitimar la identidad de todos los estudiantes en la forma que ellos y su familia lo definen"; también debe "promover un ámbito de aprendizaje en el que todos puedan expresarse y comunicarse desde su propia identidad y práctica cultural y enriquecerse mutuamente con las experiencias de otro", a la vez debe desarrollar capacidades de comunicación, diálogo e interrelación en una relación equitativa entre personas, grupos, saberes y conocimientos. Finalmente se plantea contribuir a la búsqueda de la equidad social y mejorar las condiciones de vida (En Guzmán, Mardones \& Cheuque, 2010). Lo anterior implica el desarrollo de condiciones y estrategias formativas que consideren las distintas dimensiones sobre 
las que se debe actuar para el logro de la interculturalidad, reforzando en la relación educativa aspectos identitarios, expresivos y comunicacionales que apunten al logro de una mayor equidad sociocultural. Lo anterior es un proceso complejo, ya que históricamente el sistema educativo se orienta naturalmente a la uniformidad, valiéndose de distintos dispositivos que actúan a favor de la homogenización. Así es posible distinguir distintos modelos de educación multicultural en la medida que se conjugue el interés por la afirmación hegemónica de la cultura dominante con la integración de las culturas y el reconocimiento del pluralismo cultural (García, Pulido y Montes, 1997).

Estos autores agrupan los modelos de educación multicultural de acuerdo a finalidades conforme a los diversos enfoques del concepto de cultura. Para Dietz (2012), se instala un discurso de pedagogía que da origen a múltiples modelos de educación intercultural en función de la situación, de qué parte y las finalidades que le atribuye.

La síntesis anterior deja de manifiesto que la educación intercultural ha tenido múltiples influencias generando pedagogías nacionalistas y multiculturalistas, que encierran políticas de identidad diversas. Dietz (2012) considera que "el principal obstáculo que debe enfrentar toda estrategia dirigida a interculturalizar la educación es la institución escolar y su firme arraigo, no solo dentro de la pedagogía nacionalizante, sino del propio Estado nación" (Dietz, 2012, p.209). La educación y sus herramientas administrativas, la planificación y las reglamentaciones, presentan importantes limitaciones, ya que son construidas a partir de concepciones restringidas y estereotipadas de la diversidad en los estudiantes. El otro diverso, es instituido como un problema y se invisibiliza la incapacidad de las instituciones educativas para orientarse hacia los sujetos de aprendizaje. 
ESTUDIOS DOCTORALES FEMENINOS:

Aportes desde las Ciencias Sociales y Humanas

Modelos de gestión de la diversidad educativa

\begin{tabular}{|c|c|c|c|}
\hline Tipo & Situación Inicial & Finalidad & Descripción \\
\hline $\begin{array}{l}\text { Educación Asimi- } \\
\text { ladora }\end{array}$ & $\begin{array}{l}\text { Niega la diferencia de } \\
\text { estudiantes }\end{array}$ & Educar para asimilar & $\begin{array}{l}\text { Proceso unidireccional } \\
\text { cultural de adaptación }\end{array}$ \\
\hline $\begin{array}{l}\text { Educación compen- } \\
\text { satoria }\end{array}$ & $\begin{array}{l}\text { Deprivación, hán- } \\
\text { dicaps culturales y } \\
\text { lingüísticos }\end{array}$ & Superar Hándicaps & $\begin{array}{l}\text { Afirmación hegemó- } \\
\text { nica de la cultura de } \\
\text { acogida y la diversidad } \\
\text { se patologiza }\end{array}$ \\
\hline Educación pluralista & $\begin{array}{l}\text { Comunidades con de- } \\
\text { recho a una educación } \\
\text { específica }\end{array}$ & $\begin{array}{l}\text { Enseñar cultura de } \\
\text { origen }\end{array}$ & $\begin{array}{l}\text { Pluralismo, enseñanza } \\
\text { de la lengua de origen }\end{array}$ \\
\hline Educación bicultural & $\begin{array}{l}\text { Presencia de resisten- } \\
\text { cia al nacionalismo de } \\
\text { Estado }\end{array}$ & $\begin{array}{l}\text { Asimilar y normalizar } \\
\text { la lengua dominante }\end{array}$ & Educación bilingüe \\
\hline $\begin{array}{l}\text { Educación para la } \\
\text { tolerancia }\end{array}$ & $\begin{array}{l}\text { Desde valores vigen- } \\
\text { tes incorpora lo ajeno }\end{array}$ & $\begin{array}{l}\text { Enseñar para el res- } \\
\text { peto intercultural y la } \\
\text { tolerancia }\end{array}$ & $\begin{array}{l}\text { Amplía la intercul- } \\
\text { turación a todos los } \\
\text { educandos }\end{array}$ \\
\hline $\begin{array}{l}\text { Educación antirra- } \\
\text { cista }\end{array}$ & $\begin{array}{l}\text { Parte de la constata- } \\
\text { ción de racialización } \\
\text { de la otredad }\end{array}$ & $\begin{array}{l}\text { Develar estructuras } \\
\text { que subyacen en la } \\
\text { mirada racista }\end{array}$ & $\begin{array}{l}\text { Tematiza las racializa- } \\
\text { ciones }\end{array}$ \\
\hline Pedagogía crítica & $\begin{array}{l}\text { Intervención desde } \\
\text { una visión societal } \\
\text { más amplia }\end{array}$ & $\begin{array}{l}\text { Democratizar el siste- } \\
\text { ma escolar }\end{array}$ & $\begin{array}{l}\text { Superar la acción afir- } \\
\text { mativa. Deconstruir las } \\
\text { identidades mayoritarias } \\
\text { y opresoras }\end{array}$ \\
\hline $\begin{array}{l}\text { Educación } \\
\text { intercultural com- } \\
\text { pleja }\end{array}$ & $\begin{array}{l}\text { Necesidad de incorpo- } \\
\text { rar al conjunto de los } \\
\text { educandos }\end{array}$ & $\begin{array}{l}\text { Educar para } \\
\text { interactuar }\end{array}$ & $\begin{array}{l}\text { Tematizar la heteroge- } \\
\text { neidad. } \\
\text { Competencias inter- } \\
\text { culturales a través de } \\
\text { la interacción }\end{array}$ \\
\hline $\begin{array}{l}\text { Educación y empo- } \\
\text { deramiento }\end{array}$ & $\begin{array}{l}\text { Parte de la necesidad } \\
\text { de concienciar a los } \\
\text { grupos oprimidos }\end{array}$ & $\begin{array}{l}\text { Educar para empo- } \\
\text { derar }\end{array}$ & $\begin{array}{l}\text { Elaboración de un } \\
\text { currículum diversifica- } \\
\text { do y contextualmente } \\
\text { pertinente }\end{array}$ \\
\hline $\begin{array}{l}\text { Educación inter- } \\
\text { cultural inductiva y } \\
\text { colaborativa }\end{array}$ & $\begin{array}{l}\text { Persiste colonialidad, } \\
\text { (En estructura, per- } \\
\text { cepción, conceptuali- } \\
\text { zación y práctica de la } \\
\text { diversidad) }\end{array}$ & $\begin{array}{l}\text { Descolonizar el cono- } \\
\text { cimiento }\end{array}$ & $\begin{array}{l}\text { Construcción de una } \\
\text { epistemología del sur }\end{array}$ \\
\hline
\end{tabular}

Fuente: Elaboración propia a partir Dietz, 2012

Pensando en el cambio, Sabariego (2009) considera cinco dimensiones de la educación intercultural que deben operar para la transformación: la integración del contenido, el análisis crítico del proceso de construcción del conocimiento, la reducción del prejuicio, el desarrollo de una pedagogía de la equidad, y la construcción de una cultura escolar y una estructura social 
favorables al empoderamiento de las personas en riesgo de exclusión. Relevamos la importancia de desarrollar una pedagogía de la equidad, orientada a facilitar el éxito académico de todos para conseguir una auténtica igualdad de oportunidades, independientemente de la procedencia cultural, la condición sexual, la clase social o cualquier otra diferencia individual o grupal. Lo anterior implica el desafío de pensar los procesos de enseñanza en coherencia con los estilos de aprendizaje, las diferencias culturales y el favorecimiento de relaciones de cooperación (Sabadiego, 2009).

Todo lo anterior supone una comunidad educativa consciente de las relaciones de desigualdad social y un compromiso por generar condiciones que favorezcan en los estudiantes el desarrollo de la autonomía personal y la participación social. Estas cinco dimensiones responden a distintas perspectivas de la educación intercultural, centradas en la necesidad de favorecer la cohesión social a partir de la integración de la diversidad, poniendo el acento no solo en el desarrollo de competencias por parte de los distintos, sino que, en la propia institución, sus dispositivos y actores estén orientados por este propósito. Lo anterior implica a nivel institucional, la generación de procesos que permitan el reconocimiento de la diversidad como un rasgo propio de toda sociedad y la adopción de medidas para dar acogida amplia a esta diversidad, generando experiencias formativas de calidad que las considere.

Para el docente exige el desarrollo de un conjunto de competencias interculturales, concebidas como habilidades cognitivas, afectivas y prácticas, para desenvolverse eficazmente en un medio intercultural, que le permita la comprensión crítica del contexto social y político en el que desarrolla su acción, para situar la 
experiencia educativa en un escenario más amplio y complejo. Se asume entonces una noción de interculturalidad con carácter de transversalidad que, fundamentada en el constructivismo pedagógico y el pluralismo sociocultural, aborde la pertinencia educativa, las habilidades para la convivencia y la inclusión social. Lo anterior sin dejar de lado la necesidad de adoptar modalidades críticas de educación intercultural, que consideren la deconstrucción de los discursos y develen estructuras ideológicas subyacentes, que legitiman las asimetrías entre los diversos grupos sociales.

\section{INTERCULTURALIDAD Y UNIVERSIDAD}

La diversidad cultural existente en los distintos países de América Latina demanda de la educación superior no solo el reconocimiento de la pluralidad sino la generación de condiciones para hacer efectiva la interculturalidad. No obstante, orientar a la universidad hacia la interculturalidad no es una empresa fácil; la universidad constituye una institucionalidad muy difícil de transformar, dado el arraigo que concepciones tradicionales tienen lugar en ella. En nuestra tradición universitaria existe una concepción extremadamente mono cultural y eurocéntrica, lo que se manifiesta en la manera en que se organiza su estructura, funciones y finalidades (Estermann, 2009). Generar una crítica de la universidad a este orden, desde la interculturalidad implicaría para López (2012): "imaginar una sociedad distinta que genere sus propios instrumentos teóricos y metodológicos junto con comprometerse ética y políticamente con la realización de esa sociedad" (López, 2012, p.14). Lo anterior implica situar la presencia de los antes excluidos en otra perspectiva, reconociendo las posibilidades que estos tienen de enriquecer la vida universitaria, apertura a distintos mundos simbólicos, lenguas, saberes y racionalidades de las que ellos son portadores, como posibilidades de aprendizaje y aproximación a la realidad. 
En América Latina, la universidad, en respuesta a la demanda intercultural, ha fortalecido la inclusión de estudiantes indígenas en la educación superior. Esta incorporación se ha realizado a partir de dos modelos: el primero, la creación de universidades interculturales y/o indígenas, y el segundo, interculturalizando las universidades existentes desde acciones afirmativas de educación para estudiantes de procedencia indígena (Mato, 2008; Tubino, 2012). Estas experiencias y sus niveles de desarrollo presentan a juicio de los autores fortalezas y debilidades, en tanto las universidades Interculturales tienen la ventaja de constituirse en diseños generados para un grupo particular de población y en relación con el medio, sus imitaciones tienen que ver con que los niveles de calidad no están garantizados (Tubino, 2012).

Por su parte el desarrollo de medidas de carácter afirmativo hacia grupos excluidos, sin una propuesta que considere a toda la institución, no logra permear la cultura universitaria tradicional, por lo que no genera cambios en los modos de concebir y tratar a los estudiantes que provienen de sectores sociales no habituales en la educación superior. Otro aspecto que se valora de las experiencias que fueron investigadas y sistematizadas por IESALC (Instituto Internacional para la Educación Superior América en Latina y el Caribe) es la importancia del compromiso con el aprendizaje cooperativo, para facilitar el intercambio de experiencias y el cumplimiento de objetivos académicos y relacionales. Es fundamental una mayor apertura a la diversidad, no solo a través de medidas excepcionales para facilitar el acceso, sino dando acogida a otras lecturas y cosmovisiones negadas o invisibilizadas por la cultura académica tradicional, incrementando la colaboración intercultural y la vinculación sistemática con el medio social. Lo anterior requiere que las comunidades 
universitarias asuman procesos reflexivos respecto de su quehacer y la pertinencia de la formación y la investigación para el desarrollo de la sociedad en la que se insertan localmente.

En esta perspectiva, reconocer las concepciones docentes y los discursos institucionales y constituirlas en material de análisis para aproximarse a la comprensión de la educación superior, es un camino que puede abrir posibilidades de debate sobre los cambios que la interculturalidad puede potenciar en la institucionalidad universitaria y las relaciones entre sus actores.

\section{LAS CREENCIAS COMO CONOCIMIENTO IMPLÍCITO}

Aproximarse al universo conceptual que define lo que se entiende por creencia, es una tarea compleja, por ello se optó por iniciarla recurriendo en primer lugar a un diccionario general de la lengua española. En él se define la creencia como "firme sentimiento y conformidad con una cosa. Completo crédito prestado a un hecho o noticia/religión" (Diccionario Larousse, 2000). Esta definición del concepto creencias, aunque simple y breve, entrega algunos elementos fundamentales para comprenderlo y que constituyen su núcleo esencial. En términos generales, la creencia se trataría de un elemento de humanidad, es un contenido humano, que tiene una dimensión emocional, sentimiento de convicción y conformidad con algo; ese algo puede ser un hecho o un pensamiento, una ideología, a la que subjetivamente se le da estatus de verdad, de creíble. También la definición contiene una concepción más restrictiva de creencia, aparece en el texto, homologada a un tipo particular de ella, constituida por la religión. La primera aproximación, es la que mejor permite acercarse al objeto de estudio. Así entendido, se trataría de un sentimiento de convicción y conformidad con una idea sobre la enseñanza, la práctica educativa, la diversidad de estudiantes, 
la universidad y los desafíos de interculturalidad, pero aún resulta insuficiente y difícil de visualizar, por el contenido interno y emocional que la constituye. Puede creerse cualquier cosa, y cuando se cree en algo, tendemos a actuar como si dicha creencia fuese verdadera. En esta aproximación, es posible distinguir otras dimensiones del concepto, su función ante el vacío o desconocimiento de alternativas, la creencia cumple la función de explicar un hecho. También este concepto pone en evidencia otro aspecto problemático del estudio de las creencias, cual es la presunción del estatus inferior del conocimiento al que accedería, irracional o pre-científico.

Las múltiples aproximaciones al concepto de creencia la han consagrado como objeto de preocupación de diversas disciplinas, la producción teórica que existe en torno a ella permite afirmar la relevancia que ha tenido este tema para la filosofía, la teología, la sociología y la psicología. Por su parte, Ortega y Gasset en un intento por comprenderlas, ha opuesto las creencias a las ideas: las primeras serían para él, todas aquellas cosas con las que contamos absolutamente, aunque no pensemos en ellas, por lo que constituyen la base de la vida humana. "Las creencias constituyen la base de nuestra vida, el terreno sobre el que acontece. Porque ellas nos ponen delante lo que para nosotros es la realidad misma (...) En cambio las ideas, es decir los pensamientos que tenemos sobre las cosas, no poseen en nuestra vida valor de realidad" (Ortega y Gasset, 1995, p.29).

En sociología, el estudio de las creencias como fenómeno social, ha sido recurrente Max Weber, en La política como vocación (1922) utiliza el término Glaube (creencia), tanto para referirse a la fe religiosa, como para fundar su argumentación sobre el papel que juegan en el ámbito político, el combate por las con- 
vicciones ideológicas y la fe de una persona en una causa. En otra de sus obras, La ética protestante y el espíritu del capitalismo (Weber, 1905), su tesis sobre la explicación del nacimiento del mundo moderno es elaborada en el marco de una sociología dedicada a comprender las motivaciones subjetivas de la acción humana. La tesis se funda en el análisis de la creencia, de la convicción, del conjunto de sentimientos, del ethos, del espíritu, que hizo creer que el summum bonum es ante todo ganar dinero (Diccionario sociológico, 1997).

Como vemos en forma reiterada, los autores desplazan ideas o preocupaciones en torno al tipo de conocimiento al que se accede al analizar el contenido de las creencias, por ello se incluye en este punto lo desarrollado por Lizón (2000), quien estudia los planteamientos de Boudon y señala que el autor se preocupa del carácter racional de los fundamentos de las creencias y de su contenido cognitivo, identificando distintos conjuntos de explicación de creencias, que se han cristalizado como las tendencias centrales de la tradición acumulada. La autora realiza traducción libre de esta tipología y reconstruye un esquema en el que se condensan las posturas nucleares de la tradición sociológica: Las creencias o los fenómenos de convicción atienden o a factores cognitivos que no tienen el estatus de razones, o a factores afectivos o motivacionales, o se conciben como directamente tributarias de causas culturales o biológicamente evolucionarias. El primer grupo busca hacer comprensible la creencia dando cuenta de las razones que tienen sus miembros para creer. La explicación se basaría en factores cognitivos racionales. Weber representaría esta tendencia. Para el segundo grupo, la explicación de la creencia se debe a factores cognitivos no identificados con razones, identifica como representativo de este tipo, los estudios de creencias mágicas de Lévy-Brhul (1967, en Li- 
zón, 2000) en la que el autor trabaja la idea de un pensamiento pre-lógico.

La explicación de las creencias en el grupo tres responde a factores motivacionales que se presentarían como efecto directo del sentimiento. Aquí las razones que el sujeto se da, se constituyen en un mecanismo de racionalización o un carácter ilusorio. Comparte con otros como Aronson, que distinguen entre sujeto social razonador, pero no necesariamente razonable (Lizón, 2000). En el cuarto grupo, las razones se presentarían como efectos de otros procesos, tributarias de causas de orden biológico o culturales evolucionistas y las razones que explican las creencias las obtiene el sujeto a través de procesos de socialización.

En una segunda aproximación atribuye a las explicaciones del grupo dos y tres un carácter irracional, comparten como postulados que las razones que explican la creencia vienen dadas por situaciones de otra naturaleza, que no están objetivamente fundadas, pero que tampoco pertenecen al ámbito afectivo. Boudon intentará recuperar el sentido cognitivo de estos fundamentos, conciliando las convicciones objetivamente fundadas y aquellas sustentadas en ideas frágiles, dudosas y aún falsas (Lizón, 2000). Estos planteamientos adquieren importancia para esta investigación en la medida que permiten asignar valor a las creencias, por cuanto estas representan explicaciones o razones que fundamentan la forma en que los seres humanos conciben y construyen sus visiones y concepciones del mundo, que no pueden ser desechadas por considerarlas irracionales o de menor estatus que el conocimiento científico, sino que deben ser estudiadas con el convencimiento de que analizando su contenido cognitivo, es posible deducir el material que fundamenta dichas visiones. 


\section{EL PARADIGMA DE PENSAMIENTO DEL PROFESOR}

Este paradigma asume la reflexividad del docente y la incidencia de sus concepciones en la práctica docente. En el contexto de la investigación educativa, se reconoce la importancia que tiene el conocimiento y las creencias previas que poseen los profesores en la orientación de la conducta de enseñar (Marcelo, 1993). La investigación en este campo es abundante, pero se observa en general una gran dispersión semántica, ya que se usan términos como creencia, actitud, valores, juicios, opiniones, percepciones, concepciones, preconcepciones, disposiciones, teorías implícitas, entre otros, (Pajares, 1992) que dificultarían las posibilidades de transferencia de los resultados a otros contextos o situaciones. No obstante lo anterior, que dificulta las posibilidades de comparación de las investigaciones para avanzar en la acumulación de conocimientos sobre el tema, se valora su aporte en términos que permiten poner al centro de la atención, nociones que forman parte de la visión de los docentes sobre el quehacer académico y que son muchas veces compartidas por el grupo de referencia, incidiendo en la forma en que estas personas y grupos conciben el ejercicio de su rol.

Respecto de las teorías implícitas, es posible señalar que constituyen síntesis dinámicas de conocimientos que los profesores abstraen a partir de conjuntos de experiencias relativas a la enseñanza y que según Calderón (2003), se abstraen del cúmulo de experiencias que las personas almacenan en su memoria, que aunque personales, contienen también un conjunto de ideas compartidas culturalmente y que, requieren de mediaciones para su expresión, siendo el diálogo una de ellas.

Estas características nos dan cuenta de su origen, su significación social y, por tanto, también de la posibilidad de acceder a ellas. A través de la interacción social que provoca el investiga- 
dor en el proceso de indagación de información y en el análisis de los datos, es posible por tanto su reconocimiento y la elaboración del discurso sobre ellas, Abelson (1979, citado en Calderón, 2003) identifica algunas diferencias respecto de conocimiento y creencia, las que resumimos a continuación, dada la importancia que tienen para el reconocimiento de las creencias en el discurso de los docentes.

Para Calderón (2003) los sistemas de creencias no son consensuales, no todos están de acuerdo en las mismas creencias y se aceptan distintas creencias sobre un mismo tema. Por ello es posible que en el estudio, se identifiquen diversas concepciones sobre un mismo hecho, o que en un mismo hablante subsistan diferentes creencias sobre él. Incluirían la noción de existencia, es decir, hay una convicción de que algo existe de la forma en que lo concebimos. Además, los sistemas de creencias son altamente evaluativos, tienden a constituirse en estimaciones del valor de algo y permiten su calificación de acuerdo a las expectativas que posee el autor y poseedor de ellas. También contendrían un alto grado de material episódico, no necesariamente se fundamentan en hechos e información sistemática sobre estos, sino que se basan en evidencia circunstancial que es interpretada como valiosa o certera. Junto con lo anterior, otra característica del sistema de creencias es que no todos ellos tienen el mismo grado de fuerza; la capacidad que tienen de incidir en el comportamiento del sujeto o del grupo depende de un conjunto de factores personales y de contexto que le otorgan poder de persuasión y lo vinculan con la toma de decisiones. En cambio, el conocimiento científico, requiere del consenso de una comunidad de investigadores y expertos que lo validen, adquiriendo importancia no solo la sistematicidad y rigurosidad con que ese conocimiento fue producido, sino que debe ser capaz de dar fe de su confiabilidad, validez y aplicabilidad más general. 
Kleine y Smith $(1987$, p.7) definen el concepto de creencia como una proposición simple, consciente o inconsciente, inferida de lo que una persona dice o hace, capaz de ser precedida por la frase "yo creo que" (En Hervaz C. y Martín J. 1997, p.2). Las creencias por tanto, representarían concepciones educativas de los profesores, que van organizando su mundo profesional y que inciden en sus acciones y decisiones, posibles de develar a través de lo que hacen, pero también de lo que dicen, en la medida que la palabra es uno de los principales medios a través de los que estas creencias se van elaborando, manifestando y comunicando a otros. Estas creencias tienen su origen en la experiencia de los actores, ya sea como sujeto del aprendizaje, en sus vivencias como educando o en su rol de educador a través de la experiencia docente, influirían, en mayor o menor grado, en el proceso de formación profesional que el docente realiza.

\section{EL HABITUS Y LAS CREENCIAS}

Las creencias no solo constituyen un elemento que le permite interpretar los nuevos conocimientos y el contexto en que se desempeña, sino que también incidirían en la manera de organizar su accionar como docente, elaborando una determinada forma de enfrentar los hechos y situaciones cotidianas que surgen en el ejercicio de su quehacer. Zaccagnini (2001) aporta en el mismo sentido, señalando que el docente en los diferentes contextos institucionales hilvanó su propia historia de alumno. En este camino incorporó concepciones sobre el aprendizaje, la enseñanza, la relación entre los actores, los roles entre otros. Además de su experiencia como estudiante cuando ingresa al campo laboral del ejercicio de la docencia, el docente, a juicio del autor, incorporaría un conjunto de información y claves culturales que orientan su práctica y comprensión del contexto educativo, “...nuevos códigos, vividos como mandato, son asi- 
milados por el docente, desde donde concibe: el cómo se enseña, cómo se aprende, las categorías de alumnos, la relación docente-alumno-conocimiento, docente-institución, relación conocimiento escolar-realidad social, categorización social y laboral del rol docente, etc." (Zaccagnini, 2001, en Contreras, 2011)

El mismo autor propone el habitus, uno de los conceptos centrales de la teoría sociológica de Pierre Bourdieu para abordar la influencia del contexto y las relaciones en la formación de las creencias. Este concepto que puede ser entendido como esquemas de obrar, pensar y sentir asociados a la posición social, indica que las personas, por el hecho de pertenecer a un grupo social determinado, tienden a compartir una forma de interpretar la realidad social en la que existen. El habitus estructuraría la manera en que los individuos perciben e interactúan con la realidad. Este constructo, permitiría superar la oposición entre el objetivismo y su impronta determinista y el subjetivismo con su carácter voluntarista, en la explicación de las prácticas sociales. El habitus sería entonces el conjunto de esquemas generativos a partir de los cuales los sujetos perciben el mundo y actúan en él. En palabras de Bourdieu (1972, p.178 en datos de Criado) “... el habitus se define como un sistema de disposiciones durables y transferibles -estructuras estructuradas predispuestas a funcionar como estructuras estructurantes- que integran todas las experiencias pasadas y funcionan en cada momento como matriz estructurante de las percepciones, las apreciaciones y las acciones de los agentes de cara a una coyuntura o acontecimiento que él contribuye a producir". El habitus constituiría una internalización de las estructuras, a partir de la que el grupo social en que el sujeto ha sido educado, produce pensamientos y prácticas, formando un conjunto de esquemas de percepción, categorización y apreciación de las situaciones. A partir de ellas, 
los agentes sociales van realizando opciones para su práctica, no determinados, sino orientados hacia ellas. El habitus entonces, actúa como una disposición que se reactiva en función de los contextos y las relaciones que se establecen, originando también una multiplicidad de prácticas, en las que pueden identificarse estos elementos que la estructuran y que son comunes a los miembros de un determinado grupo social. Dado que el habitus remite a los procesos de socialización experimentados por los sujetos, para explicar dichas prácticas, es necesario no remitirse solo al presente, sino considerar la dimensión histórica en que se fueron originando estas estructuras.

Para Arzola (2004) todo fenómeno educativo es producto de acciones, decisiones, actitudes, comportamientos, creencias de actores individuales que pueden ser comprendidas y constituidas en objeto de las Ciencias Sociales. Las razones y argumentos a los cuales aluden los individuos como fundamentos de sus acciones no tienen una sola naturaleza y no responden siempre a una lógica instrumental o de costo-beneficio como algunos han señalado; la naturaleza de las creencias y argumentos puede ser, entre otras, de carácter emocional y afectiva, o bien estar basadas en la adhesión a un valor o a una norma (Boudon, 2003 en Latorre 2009). Hay, pues, una racionalidad "subjetiva", construida a partir de la significación que le otorga el actor a sus acciones, creencias y actitudes. Las creencias del docente o sus concepciones respecto de la equidad y la inclusión de la diversidad, tienen un componente valórico y prescriptivo que le permiten orientar su acción y juzgar situaciones, además de elementos cognitivos y emocionales.

En este apartado se ha establecido el valor de las creencias como contenido y fundamentos de la acción docente. Indepen- 
dientemente de la racionalidad de su contenido, se constituyen como contenidos que fundamentan la acción y práctica docente y que es necesario develar para comprender dichas prácticas, identificando espacios posibles, para promover la reflexión sobre ellas y la modificación de aquellas que dificultan el desarrollo de la docencia en un contexto de rápidas transformaciones.

Las acciones de carácter afirmativo e inclusivo de la diversidad estudiantil requieren el develamiento de estas creencias que constituyen la cultura docente y que inciden no solo en la calidad de los procesos de aprendizaje sino en las relaciones que se establecen en su desarrollo.

\section{RECONOCIMIENTO E INTERCULTURALIDAD}

En educación, las teorías de justicia se han orientado fundamentalmente hacia el logro de la equidad educativa entendida como igualdad de oportunidades en función de sus méritos. Junto a las políticas de la justicia redistributiva, ha surgido con fuerza la perspectiva del reconocimiento que aboga por el derecho a la valoración social de los distintos grupos sociales y culturales. Benhabib (2006) plantea que hoy nos enfrentamos a un escenario social en que la cultura y las identidades culturales se constituyen en el centro de la reflexión ética y política de las sociedades modernas. Las luchas por el reconocimiento, los movimientos por la identidad y la diferencia o la ciudadanía multicultural, dan cuenta de un nuevo imaginario en que la identidad cultural se releva en el discurso político, poniendo en tensión las definiciones legitimadas en las democracias constitucionales, al exigir reivindicaciones para grupos que abogan por la necesidad de reconocimiento de identidades basadas en el género, la etnia y el lenguaje. En el contexto de este trabajo, nos parece que podríamos incluir en este listado las identidades basadas en el 
nivel socioeconómico, en la etapa del ciclo vital, ampliando de este modo la necesidad de reconocimiento a otros grupos que, como los pobres o los jóvenes, tienen una posición subordinada en nuestra sociedad y cuyas luchas y reivindicaciones no se han constituido en movimientos visibles y autónomos.

La complejidad y la controversia son inherentes a toda cultura, lo que les da un carácter dinámico y flexible. En este sentido es posible pensar en la posibilidad de culturas juveniles, asociadas a la manera en que los jóvenes se manifiestan socialmente. Asumiendo entonces la presencia de una cultura juvenil, que en tanto complejidad y controversia, se ha ido develando en el ámbito público, es posible plantearse la pregunta por las posibilidades de reconocimiento de la diferencia y las posibilidades de inclusión en el sistema de educación superior de este grupo, en un espacio sociocultural en el que se observa el predominio de una cultura adulto céntrica, con mayores oportunidades de despliegue material y simbólico. El modo tradicional de concebir la enseñanza en la universidad, revela una resistencia por parte de la academia a incorporar el cambio de usuario de la educación superior, desconociendo el valor del otro más allá de su capital cultural. La importancia del reconocimiento como valoración social del otro y su potencial emancipador ha sido desarrollado por Axel Honneth, propuesta teórica que se presenta a continuación.

\section{TEORÍA DEL RECONOCIMIENTO DE HONNETH}

Honneth, influenciado por las ideas de Hegel, en la teoría del reconocimiento que sustenta, intenta subsanar las limitaciones de las teorías de la justicia distributiva. En esta perspectiva el ideal de justicia es en su concepción, más que la distribución equitativa de recursos, debe incorporar la necesidad que tienen los sujetos de reconocerse mutuamente. Mientras que Nancy 
Fraser (1996) y Taylor (2001) adoptan una postura dualista en la concepción de justicia en la que redistribución y reconocimiento son dos conceptos centrales e irreductibles, Honneth (2006) desde una perspectiva monista de justicia, formula un concepto de reconocimiento que incluye los conflictos atribuidos a cuestiones de justicia distributiva y que trasciende lo meramente cultural. Para Honneth (2010) los conflictos de distribución son siempre luchas simbólicas por la legitimidad del dispositivo sociocultural que determina el valor de actividades, cualidades y aportaciones sociales. De este modo, la lucha por la distribución no difiere de la lucha por el reconocimiento, ya que el conflicto se traduce en una pugna por la definición cultural que hace que una actividad sea socialmente necesaria y valiosa. En esta concepción de justicia las categorías centrales ya no son "la distribución equitativa o la igualdad de bienes sino la dignidad y el respeto" (Honneth, 2010, p.10).

Honneth (2009) plantea que las luchas sociales y las demandas de justicia tienen su origen en el padecimiento de experiencias de menosprecio o privación de reconocimiento que afectan a las personas a lo largo de su vida. Dentro de las condiciones intersubjetivas para el logro de la identidad, se encuentran las formas de comunicación social en las que el individuo crece y aprende a concebirse como miembro igualitario y a la vez singular de la sociedad. Para el autor, las patologías de la sociedad contemporánea pueden ser examinadas a través de estos procesos comunicativos. "Si estas formas de comunicación son de una cualidad tal que no proveen el grado necesario de reconocimiento para poder cumplir con esas diversas tareas de identidad, esto debe considerarse un indicador de la evolución desacertada de la sociedad" (Honneth, 2009, p.266). No obstante, la centralidad que tiene la comunicación entre quienes participan 
del espacio social de referencia, Honneth advierte en su propuesta que el paradigma de la comunicación es insuficiente para constituirse en una Teoría Critica de la sociedad en la medida que se concibe solo en términos lingüísticos y desde racionalidades en juego, sino que debe examinarse en su capacidad para dar cuenta de las deficiencias en la estructura social de reconocimiento. De este modo una teoría crítica útil en el análisis social actual, debiera develar causas en la estructura que generan distorsiones en la estructura social del reconocimiento, "un diagnóstico de la sociedad que estuviera en condiciones de revelar un momento de la trascendencia intramundana" (Honneth, 2009, p.251). Es decir, una teoría que permita establecer la vinculación regular entre ciertas experiencias de desprecio vivenciadas por los sujetos y la evolución estructural de la sociedad. El autor, de 82 esta manera, va planteando una propuesta normativa en que el cambio societal o su evolución se fundamentan en las pretensiones recíprocas de reconocimiento de los sujetos en sus relaciones y su lucha por alcanzarlas.

El poder de este enfoque se situaría en la posibilidad de visualizar situaciones de menosprecio social experimentadas como injusticia y constituirlas en objeto de movilización emancipatoria. Remitiéndose a Hegel, Honneth distingue tres formas de reconocimiento social que considera condiciones comunicativas para el logro de una "formación atinada de la identidad" (Honneth, 2009, p.267). Estas formas o esferas del reconocimiento son el afecto emocional en las relaciones sociales íntimas como el amor y la amistad, el reconocimiento jurídico como miembros de una sociedad que es moralmente responsable de sus acciones y la valoración social del desempeño y las capacidades individuales (Honeth, 2009, p.267). 
Cada una de estas esferas constituye un estadio de integración social en el que el sujeto va siendo reconocido de un modo distinto en su identidad personal. En la esfera del amor, el cuidado amoroso de las relaciones primarias significativas se orienta a la satisfacción de necesidades de las personas y el logro de su bienestar. En esta fase será reconocido como un individuo aquel cuyas necesidades y deseos sean de un valor singular para otra persona. La libertad y la igualdad de las personas en una comunidad son reconocidas por el derecho. Este estadio representa el ideal kantiano, todos son igualmente dignos y deben valer como un fin en sí mismo (Fascioli, 2011). No obstante, para Honneth el reconocimiento jurídico no es suficiente, además de compartir el estatus de ciudadano con los miembros de su comunidad, requiere del reconocimiento de sus capacidades en el contexto de interacción con otros en su desempeño. De este modo el tercer tipo de reconocimiento lo constituye la valoración social concebida como la medida de estimación que un individuo alcanza por la forma que adquiere su autorrealización identitaria y su contribución a las metas sociales de su comunidad. La solidaridad y la lealtad son los valores que permiten el reconocimiento recíproco en este ámbito. Es "en esta esfera comunitaria de la eticidad que se establece una forma de reconocimiento que debe permitir a los sujetos continuar valorándose recíprocamente en las cualidades que contribuyen a la reproducción del orden social" (Honneth, 1996, p.8). La solidaridad otorga al individuo la estima social para reconocerse en su aporte a la sociedad. La comunidad entonces se constituye por su naturaleza relacional, donde se distinguen diferentes dimensiones sociales y formas de reconocimiento recíproco basadas en el amor, los derechos y la solidaridad.

Por su parte el autor distingue tres formas de desprecio que 
implican la ausencia de autoconfianza, autorrespeto y autoestima. Tanto los malos tratos, como la violación amenazan la integridad física; la exclusión y el despojamiento de derechos, la integridad social y; la humillación y la ofensa el honor y la dignidad de los miembros en tanto capaces de contribuir a la comunidad" (Sampaio, 2010, p.26). Las transgresiones descritas constituyen experiencias de injusticia, caracterizadas por la falta de reconocimiento debido. Esta falta y la consiguiente demanda por el reconocimiento recíproco, deviene en procesos conflictivos, que constituidos en luchas moralmente motivadas orientan los cambios sociales.

La teoría del reconocimiento así concebida aporta una nueva perspectiva en la conceptualización de la justicia social, ahora entendida como garantía de las condiciones sociales para el reconocimiento mutuo. La valoración social de un individuo se mide en gran parte por su aporte a la sociedad en la forma de un trabajo formalmente organizado. Es decir, el respeto por la contribución o desempeño que cada sujeto proporciona al conjunto de la sociedad, basado en una comunidad de valores históricamente dados y compartidos.

Aun cuando Honneth no se refiere directamente a la educación como una esfera de apreciación social, es posible examinarla a partir de la perspectiva del reconocimiento considerando diversos puntos de entrada. En este sentido y siguiendo lo propuesto por Hernández (2007), establece una relación desde tres dimensiones. Como institución, presenta ciertas contradicciones como la pretensión de universalidad de sus finalidades y la adopción de una estructura como sistema educativo presidido por la institución universitaria, pero no es posible negar a la base de esta institución una cierta generalización del reconocimiento 
(Hernández, 2007). La institución educativa moderna se organiza a partir de dos principios que orientan la valoración social de los sujetos al interior de ella, el principio de igualdad y el de mérito, desde allí su importancia como fuente de reconocimiento social. En la educación como campo y en consideración a lo propuesto por Bourdieu, también es posible reconocer este vínculo, ya que si el campo queda definido por reglas que determinan la distribución de capital simbólico, y del resto de capitales, se podría entender que algunas de estas reglas implicarían procesos de cosificación, desprecio u olvido en el marco de la violencia simbólica con que se asocia la educación. También se trata de un ámbito social que acoge procesos de reconocimiento y desconocimiento que se originan en otras instituciones o campos sociales (Hernández, 2007). La estructura, organización y cultura institucional en educación constituyen una importante fuente de reconocimiento, en ella se realizan procesos de selección y distribución por rendimiento y mérito que legitiman ciertas desigualdades, no solo educativas sino también sociales.

Para el autor en la era socialdemócrata se observa una expansión de las normas de reconocimiento en todas las esferas (Honneth, 2010). Lo anterior se debilita cuando se instala lo que él denomina la revolución neoliberal, "bajo la creciente presión del aprovechamiento capitalista forzoso, los patrones de interpretación institucionalizados del individualismo, del derecho, del desempeño y del amor se transforman de una manera paradójica" (Honneth, 2010, p.402). El autor distingue en este punto el uso de vocabulario emancipador y pérdida por parte de las instituciones de su contenido original bajo la influencia del capitalismo expansivo y "etificado", que ha logrado formular nuevas justificaciones de desigualdad, injusticia o perjuicio social. El mérito 
individual o su contraparte son erigidos como factores causales de una integración exitosa a la esfera de valoración social del desempeño o de la exclusión de la misma, lo que claramente se puede apreciar en el sistema educativo y la legitimación del mérito.

La Teoría del Reconocimiento nos permite establecer que, además de las relaciones jurídicas que instituyen derechos y poder de acción a los individuos, las otras esferas también generan posibilidades de autorrealización. Las relaciones íntimas de afecto y los ámbitos del desempeño y la valoración social son constituidas como "mutualidades vinculantes" que fomentan la autonomía y confianza en sí mismo, así como también la pertenencia y valoración social de los miembros de una de-

86 terminada comunidad. De allí la importancia de esta perspectiva en la educación superior en tanto modelo de análisis que permite establecer articulaciones entre las experiencias individuales, las estructuras sociales, y los modelos de relaciones de reconocimiento específicos que cada sociedad promueve. Los estudiantes pueden experimentar en su proceso de formación en la educación superior, situaciones de menosprecio cuando los docentes juzgan negativamente su valor y capacidad social. La falta de valorización social se manifestará en la definición del estudiante a partir del déficit, la incompetencia o la inmadurez, constituyéndose en objeto de deslegitimación de su presencia en este nivel de enseñanza.

\section{METODOLOGÍA}

A partir de un marco de referencia conceptual concebido como inicial y abierto, el estudio se propone como objetivos reconocer las creencias y presunciones que los docentes tienen 
sobre el aprendizaje, la enseñanza, su rol, la formación docente en el ámbito universitario y analizarlas en la perspectiva de aportar elementos que puedan orientar la intervención en estos procesos. La investigación desarrollada tiene un carácter cualitativo en la que es posible identificar las características definidas por Fraenkel y Wallen (1996 en Vera, 2006), que describen las particularidades de los estudios cualitativos y que se adecúan a las propiedades que tiene este estudio. Para abordar las presunciones y/o creencias de los docentes, la narración se constituye en una forma de aproximación, ya que a través de ella los entrevistados dieron cuenta de sus supuestos, opiniones, creencias, que constituyen el conocimiento implícito sobre el que estructura su relación con los estudiantes y su quehacer en la enseñanza.

El método utilizado es el estudio de casos; se estudia el discurso de docentes formados inicialmente en disciplinas distintas a la pedagogía, pertenecientes a una universidad chilena, privada, católica y de tamaño medio. La información se recolecta a través de entrevistas semiestructuradas, basadas en "una guía de asuntos o preguntas y el entrevistador tiene la libertad de introducir preguntas adicionales para precisar conceptos $u$ obtener información sobre los temas deseados" (Hernández, 2007, p.455). El análisis de los datos es fundamentalmente inductivo; a partir del relato es posible hacer emerger un nuevo discurso que permita avanzar en la comprensión de la situación. En concordancia con el método de estudio seleccionado, la información fue analizada a partir del análisis hermenéutico, lo que supone un rescate de los elementos del sujeto por sobre aquellos hechos externos a él. En este sentido, debe destacarse que dicho análisis toma como eje fundamental el proceso de interpretación (Cárcamo, 2005). 


\section{PRINCIPALES RESULTADOS}

En el discurso y en los proyectos institucionales, es posible deducir que en el imaginario docente y en las definiciones que se realizan desde los niveles superiores de las universidades en estudio, la concepción que ellos tienen respecto de lo que debe ser una universidad responde a visiones tradicionales en tensión con las transformaciones que ha experimentado la educación superior en Chile y el mundo. La primera visión que emerge es la de una universidad tradicional de carácter científico en que las universidades existen para hacer investigación, cultivar un saber y/o conocimiento, más propia de las universidades modernas, entre las que se destaca el modelo alemán y el francés. Este último modelo influencia el desarrollo de la universidad latinoamericana que, en fases posteriores a la colonial, se vinculan con un

88 cometido esencial atribuido al sector público: el de desempeñarse como estado docente, responsable de la educación nacional (Arocena, 2004). Es clara la coincidencia entre los entrevistados y los proyectos educativos que las universidades existen socialmente para producir el conocimiento científico y el desarrollo del pensamiento, junto con la formación de profesionales orientados al servicio del país. Estas percepciones, que dan cuenta del "deber ser" que se construye como horizonte para las universidades, poco tienen que ver con las condiciones de posibilidad que ofrece el sistema de educación superior hoy, con importante financiamiento privado y retracción de la investigación, ámbito en el que las propias instituciones no han logrado proyectarse. Junto con este imaginario de la universidad tradicional, los docentes, a través de sus trayectorias vitales, profesionales y académicas, han construido un contexto de la educación en el que se evidencian importantes cambios situados con posterioridad a la década del ochenta. El modelo económico neoliberal y las 
lógicas que este impone se constituyen en el discurso docente como el icono de las transformaciones. Desde allí se destacan como fenómenos transversales, la expansión del sistema y la masificación del acceso en este nivel de enseñanza, la diversificación y estratificación que da origen a múltiples instituciones, cuya diversidad se origina primero en términos sistémicos al dar cabida a diversos modos organizacionales programáticos y reputacionales, siendo las universidades una de ellas (Brunner, 2013). La información que emergió como producto de las entrevistas realizadas a los informantes, deja de manifiesto altos niveles de incorporación por parte de los docentes respecto de los límites que el actual modelo económico y de desarrollo impone al rol social del Estado y a las universidades. No obstante la presencia de un modelo que se impone, existen tensiones entre la tendencia histórica que define a las universidades desde otro lugar, vinculada a la producción del conocimiento y la postura neoliberal. Esta tensión se expresa, entre otras formas, en la aspiración a un espacio universitario más orientado al debate, a la confrontación de ideas y a la producción de conocimiento.

Desde la perspectiva intercultural, se ha puesto de manifiesto el carácter monocultural y eurocéntrico del modelo estándar de "universidad" que se construye como ideario (Estermann, 2009; Schmelkes, 2012; Tubino, 2005; López, 2012). Los autores plantean que, independientemente de dónde se estudie, el currículo de los estudios académicos, los títulos universitarios, los estándares de investigación, la terminología técnica y el procedimiento de construcción del conocimiento son más o menos idénticos. Esta tendencia a uniformizar los estudios universitarios se ha defendido históricamente en consideración a una academicidad de rango "universal" (Estermann, 2009). Para interculturalizar la 
universidad, se considera necesario "dar cabida a las lenguas y culturas de los subalternizados, reconciliarse con la diversidad étnico-cultural de la sociedad, abrirse en diálogo intercultural a la riqueza humana y convertirse ella misma en taller permanente de elaboración de teorías y estrategias para la convivencia intercultural" (López, 2012, p.21). La interculturalidad es, sino negada, invisibilizada en nuestro país, por lo que avanzar en esta línea es una tarea compleja que implica trabajar por la construcción de una sociedad distinta. Para López (2012, p.20) no hacerlo significaría renunciar "a una de las funciones constitutivas de la universidad: la crítica propositiva”.

Estos modos tradicionales de concebir la universidad se trasladan también a la manera en que se conciben sus actores. El perfil y las condiciones de los docentes y estudiantes son evaluados a partir de la distancia que se tiene con "ese de antes". Surge la tensión en la forma en que los entrevistados conciben el campo de la educación superior y la posición de los docentes en él, reflejando también su propio lugar en el sistema. El estatus de un docente que ha ido perdiendo influencia en la construcción del proyecto educativo, proceso fuertemente influenciado por demandas de las agencias internacionales que definen cómo formar a los profesionales del mundo globalizado. Desde la perspectiva de la teoría del reconocimiento, los estudiantes no tradicionales, son poco valorados en el mundo académico puesto que sus capacidades son invisibilizadas y el discurso que se construye sobre ellos da cuenta de formas que van en la dirección de cierto menosprecio social. El cuadro siguiente permite graficar en la esfera de valoración social la incidencia de las creencias docentes en los patrones de reconocimiento intersubjetivo. 


\begin{tabular}{|c|c|c|}
\hline $\begin{array}{l}\text { Dimensión personalidad } \\
\text { (Estudiante) }\end{array}$ & $\begin{array}{l}\text { Cualidades } \\
\text { y capacidades }\end{array}$ & $\begin{array}{l}\text { Cualidades y capacidades } \\
\text { atribuidas al estudiante que } \\
\text { ingresa a universidades con } \\
\text { proyecto de inclusión. }\end{array}$ \\
\hline Formas reconocimiento & $\begin{array}{l}\text { Comunidad de valor en el } \\
\text { proyecto institucional }\end{array}$ & $\begin{array}{l}\text { Valoraciones docentes de las } \\
\text { metas de equidad e inclusión } \\
\text { en el proyecto institucional. }\end{array}$ \\
\hline Autorrealización & $\begin{array}{l}\text { Autonomía, autoestima, } \\
\text { pertenencia }\end{array}$ & $\begin{array}{l}\text { Vinculación de la acción do- } \\
\text { cente procesos de desarrollo } \\
\text { académico y social de los } \\
\text { estudiantes }\end{array}$ \\
\hline Potencial de desarrollo & $\begin{array}{l}\text { Individuación, } \\
\text { igualación }\end{array}$ & $\begin{array}{l}\text { Vinculación de la acción institu- } \\
\text { cional y docente a procesos de } \\
\text { igualación de oportunidades }\end{array}$ \\
\hline Formas de menosprecio & $\begin{array}{l}\text { Invisibilidad, } \\
\text { estigmatización }\end{array}$ & $\begin{array}{l}\text { Atribuciones realizadas a los } \\
\text { estudiantes y reconocimiento } \\
\text { de singularidades }\end{array}$ \\
\hline Amenazas a la personalidad & Dignidad & $\begin{array}{l}\text { Acciones que amenazan el re- } \\
\text { conocimiento de los estudiantes }\end{array}$ \\
\hline
\end{tabular}

Fuente: Elaboración propia con base en esferas del Reconocimiento de Honneth en Tello (2011)

El estudiante universitario es construido a partir de un conjunto de expectativas de lo que debe ser un estudiante universitario, tomando como referencia la propia experiencia docente en su época universitaria. De este modo se espera un estudiante con competencias académicas y motivación genuina por el conocimiento. Los estudiantes, en el escenario de las universidades estudiadas, son construidos a partir de los imaginarios docentes, como un joven con importantes deficiencias en términos de capacidades para enfrentar las tareas propias de esta etapa. Lo anterior es tremendamente complejo si asumimos que la no selectividad se constituye en una opción institucional, expresada en el proyecto de las universidades en estudio como inclusividad. Se observa tensión en la relación de estos docentes con sus estudiantes, mediada por las expectativas que tienen de ellos y su propia capacidad de producir mejores condiciones de equidad e inclusión. Un aspecto que a juicio de los docentes 
es clave en el proceso de aprendizaje, es el capital cultural del estudiante. Este es constituido a partir del déficit, "ser primera generación en la universidad", "la carencia de capital cultural" es la marca común y el puntaje en las pruebas de selección universitaria el marcador. Las desigualdades sociales aparecen como disparidad de talentos individuales, o sea, como desigualdades naturales. El privilegio es convertido en mérito (Ezcurra, 2007) y en la explicación del fracaso académico, el principal responsable es el estudiante.

No obstante, el reconocimiento de una cierta desigualdad de origen, es importante abrir el marco explicativo del bajo rendimiento a otras variables entre las que se encuentran aspectos institucionales y relacionales, así como también los métodos y estrategias pedagógicas apropiadas para el logro del aprendizaje. Brunner (2008), analizando las propuestas de Bourdieu para superar las desigualdades de origen en la educación, establece la necesidad de ofrecer a los estudiantes herramientas de trabajo intelectual y desarrollar métodos racionales de trabajo para contribuir a reducir las diferencias "ligadas a la herencia cultural" (Brunner, 2008). Para Bourdieu y Passeron, "toda democratización real supone que se los enseñe allí donde los más desfavorecidos pueden adquirirlos" (Bourdieu y Passeron [1964]2010, p.110). Lo anterior requiere de una pedagogía racional "subordinada al conocimiento que se tenga de la desigualdad socialmente condicionada y a la decisión de reducirla" (p.111). Sin dejar de lado explicaciones respecto al origen de estas desigualdades, a las instituciones universitarias también les cabe un rol en el modo de abordar estas diferencias para mejorar los resultados estudiantiles. Para Ezcurra, el habitus académico puede movilizarse y cambiar a partir del reconocimiento de la situación, y la reflexión sobre formas de abordaje desde la institución, teniendo 
como centro la enseñanza, y con foco en el primer año. Para la autora el objetivo debe orientarse no solo a atender a los estudiantes identificados como portadores del problema, sino romper con el habitus organizativo dominante, apartir del reconocimiento de las desigualdades culturales (Ezcurra, 2011).

También la dimensión personal es foco de desaprobación; los docentes construyen al estudiante universitario desde la inmadurez e incluso la infantilización. Imaginario que comparten con los jóvenes como categoría social, habitualmente construidos desde ese lugar (Aliaga \& Escobar, 2004). En lo político también se observa un modo de construcción negativo de la figura del estudiante y sus manifestaciones. Las movilizaciones estudiantiles como elemento de coyuntura les dificulta la definición de los estudiantes desde el imaginario de la apatía o el "no estoy ni ahi"3; produciéndose un desplazamiento de esta creencia hacia el cuestionamiento por las formas de acción que ponen en juego los estudiantes; "revolucionarios de cartón", término acuñado por uno de los docentes que da cuenta de la dificultad social para visibilizar positivamente a los estudiantes también en el ámbito de la participación. Estaríamos frente a lo que se entiende por invisibilización juvenil "la situación en la que no se reconoce protagonismo, historicidad y relevancia en los discursos y acciones de intervención por parte de instituciones o individuos" (Aliaga, Escobar, 2004). Los estudiantes universitarios comparten con los jóvenes las creencias e imaginarios que se han construido e instituido sobre este grupo social. El tránsito necesario entonces es la construcción del otro desde otro lugar, ya no desde aquello que no es, "maduro, motivado, buen lector", sino a partir de una identidad dinámica y que tiene múltiples dimensiones, "joven, ur-

3 Que denota la indiferencia de los jóvenes con la cosa pública y la política tradicional. 
bano, clase media baja y/o emergente, con un capital cultural distinto" De Garay (2004). El desconocimiento tanto de las múltiples racionalidades que operan en los jóvenes en relación a sus prácticas estudiantiles, así como de ciertos aspectos del proceso de integración académica, provoca que estén ausentes políticas específicas que atiendan a la heterogeneidad social (García, 2006). La tendencia de los docentes del estudio a concebir a los estudiantes en una primera aproximación como homogéneos, invisibiliza las diferencias en términos de género, trabajo, roles familiares, opciones estéticas y políticas, entre otros, que lo constituyen más allá de su capital cultural de origen.

Las creencias docentes y su manera de concebir al estudiante universitario que tienen en sus aulas, tendrá incidencia en una de las esferas del reconocimiento referida a la valoración social del desempeño y las capacidades individuales de los sujetos (Honneth, 2010, p.267). Para Honneth, dentro de las condiciones intersubjetivas para el logro de la identidad se encuentran las formas de comunicación social en las que el individuo crece y aprende a concebirse como miembro igualitario y a la vez singular de la sociedad. Señala además que "Si estas formas de comunicación son de una cualidad tal que no proveen el grado necesario de reconocimiento para poder cumplir con esas diversas tareas de identidad, esto debe considerarse un indicador de la evolución desacertada de la sociedad" (Honneth, 2010, p.266).

La construcción del estudiante desde el déficit y la falta de legitimidad que se atribuye al acceso a la educación superior, sin haber superado patrones estrictos de selectividad como el mayor desempeño en las pruebas de selección universitaria (PSU), vulnera las posibilidades de la valoración social concebida como la medida de estimación que un individuo alcanza por la forma 
que adquiere su autorrealización identitaria y su contribución a las metas sociales. La falta de valorización social se manifestará en la definición del estudiante a partir del déficit, la incompetencia o la inmadurez, lo que se observa en la retórica docente y su representación del estudiante.

La equidad en la educación superior ha sido concebida por las universidades en estudio como la posibilidad de que los diferentes sectores sociales accedan a la universidad. Las condiciones institucionales son percibidas como favorables para la generación de contextos equitativos, en la medida que se definen condiciones especiales para favorecer la admisión de grupos tradicionalmente excluidos de la educación superior. No obstante, las medidas pro equidad generadas por las universidades desde el punto de vista económico son consideradas insuficientes. La demanda de ayudas o becas sobrepasa las posibilidades institucionales de aportar sin poner en riesgo la sustentabilidad del proyecto institucional. Para los docentes, el rol de la Universidad como actor que genera equidad, requiere de políticas públicas que intencionen apoyos materiales y académicos a los estudiantes y a las universidades inclusivas. En general, los docentes observan limitadas sus posibilidades de incidencia en pro de la equidad educativa; las brechas de los estudiantes han de ser resueltas antes por la educación preuniversitaria o por la institución y sus unidades técnicas. Lo anterior deja de manifiesto la creencia de que las posibilidades de mejoramiento de los aprendizajes y la superación de las carencias de los estudiantes dependen de muchas variables que quedan fuera del control docente, clausurando las posibilidades de asumir un rol protagónico en esta empresa. No obstante lo anterior, un punto de fractura que aparece en los contenidos y puede ser potenciado desde el ejercicio docente en la perspectiva de de- 
sarrollar mejores condiciones para la equidad en el ejercicio de la docencia, refiere a la preocupación por realizar evaluaciones justas. Se desliza en el discurso preguntas sobre los niveles de exigencia que son posibles sin perder calidad y cómo considerar en este caso la igualdad o heterogeneidad de los estudiantes para estimar el logro de los aprendizajes. A partir de este tema es posible abrir el debate docente por la justicia educativa y deconstruir sus imaginarios respecto de la calidad académica de sus estudiantes y el cuestionamiento de los principios tradicionales de la igualdad de oportunidades y el mérito personal como bases de la equidad.

La tríada desigualdad, diferencia y diversidad son conceptos que en los discursos docentes y en los proyectos institucionales son utilizados para dar cuenta de problemas que se evidencian en la sociedad chilena o para indicar un carácter identitario de los proyectos. Dietz (2012), al analizar los giros de los estudios culturales y las implicaciones conceptuales y complementariedades de estos tres términos, señala que situarse desde cada uno de ellos trae consecuencias en el modo de concebir las situaciones y su tratamiento. De este modo, a la desigualdad le atribuye un carácter estructural, la necesidad de concurrencia de distintas disciplinas y un modo vertical y ajeno de aproximación. Desde el punto de vista de la educación, esta forma de aproximación contribuye a la desigualdad educativa en un conjunto de carencias de origen estructural y atribuye a la educación un rol compensatorio en esta desigualdad de oportunidades. En la investigación, esta manera de abordaje queda claramente esbozada en el discurso docente y en el modo en que se explican los problemas de equidad en este nivel de enseñanza y sus posibilidades de actuación. No obstante, también en el discurso docente esta convicción concurre conjuntamente con una apreciación 
de un sistema diversificado y estratificado que pone en riesgo la igualdad de oportunidades en la medida que no se garantiza la calidad de la oferta educativa, constituyéndose esta estimación en un punto de fuga para cuestionar la posibilidad de equidad de las universidades con proyectos de inclusión.

Una lectura del "otro estudiante desde la diferencia" está prácticamente ausente en el discurso; el otro no es constituido como diferente, sino que en relación a lo propio y, en ese sentido, no resulta otro, sino un sí mismo incompleto. Esta ausencia podría impedirle reconocer al otro en su particularidad y hacer del proceso de formación un espacio de reconocimiento de sus identidades y el fortalecimiento de la valoración de los sujetos. Finalmente, la construcción del fenómeno de la expansión universitaria desde la diversidad, es identificada con mayor claridad en la totalidad del sistema de educación superior, pero en las propias instituciones la advertencia de la diversidad no surge sino en una segunda aproximación. Desde allí se construye la diversidad de estilos y necesidades de aprendizaje como un problema que debe ser gestionado a través de la docencia. A partir de los modos en que los docentes y las instituciones significan y gestionan la diversidad estudiantil y los problemas de equidad de la educación superior, no es fácil estimar las posibilidades que tiene la educación intercultural universitaria en este contexto. Asumir la perspectiva intercultural es una tarea de enorme envergadura, ya que implica, en primer lugar, imaginar una sociedad distinta, una sociedad en la que han de transformarse los modos de hacer, saber y relacionarse desde formas excluyentes a otras capaces de convocar y co-construir nuevos haceres y saberes.

La democratización de la educación superior, junto con el in- 
cremento del acceso a ella de grupos tradicionalmente excluidos, implica asumir una creciente heterogeneidad de identidades e intereses en el sistema, por lo que es necesario poner en discusión los consensos en torno al sentido dado a la formación, acogiendo la particularidad de los sujetos. Debilitada la misión fundacional, la universidad requiere construir nuevas narrativas sobre su existencia social que consideren la equidad y la inclusión social de la diversidad como horizontes normativos de su quehacer. El concepto de reconocimiento tiene un carácter expresivo y constitutivo en la medida que las instituciones no solo expresan, sino que producen relaciones de reconocimiento o denegación de él. En ese contexto, la identificación de situaciones de menosprecio releva estructuras de interacción y principios normativos que orientan la vida institucional y que están a la base de situaciones de injusticia social. En esta perspectiva, tienen un potencial reivindicativo y emancipador que Honneth (2010) le atribuye en la lucha por el reconocimiento.

\section{REFERENCIAS BIBLIOGRÁFICAS}

Aliaga, F. \& Escobar, G. (2004). El imaginario social del joven en Chile. Congreso Internacional, XIII Ciclo de Estudio sobre el Imaginario. Espacios imaginarios y transculturalidad. Brasil: Universidad Federal de Pernambuco.

Arocena, R. (2004). Las reformas de la Educación superior y los problemas del desarrollo en América Latina. Educação \& Sociedade, 25(88), 915-936. Disponible en http://www.redalyc. org/articulo.oa?id=87314214013

Artavia, C. \& Cascante, L. (2009). Componentes teóricos de la pedagogía intercultural como práctica docente. Revista Electrónica Educare, Costa Rica.

Arzola, S. (2004). ¿Podemos comprender los problemas educativos a partir de la acción de los actores sociales? (Aportes 
desde la Sociología de la Acción) Seminario Modelos de Producción de Calidad en Educación, Documento No 6.

Ausubel D., Novak, J. \& Hanesian, H. (2001) Psicología Educativa, un punto de vista cognoscitivo. México: Trillas.

Baeza, J. (2009). Jóvenes de Chile y el desafío de una universidad para los pobres. Boletín Edición Especial 1, septiembre 2009. Santiago de Chile: Pastoral Universidad Católica Silva Henríquez.

Barría, N. (2009). Una mirada a la educación desde la diversidad. Recuperado de: http://claudio.aprenderapensar. net/2009/07/29/la-diversidad-en-el-aula/

Benhabib, S. (2006). Las reivindicaciones de la cultura. Igualdad y diversidad en la era global. Buenos Aires: Katz.

Bonal, X. (2002). Globalización y política educativa: un análisis crítico de la agenda del Banco Mundial para América Latina, Revista Mexicana de investigación educativa, 64(3), julio-septiembre, 3-35.

Boudieu, P. (1972). Esquisse d' une theorie de la pratique. Droz. Genéve, Paris En Criado, E. Diccionario Crítico de las Ciencias Sociales Terminología Científico-Social. Editores Plaza y Valdés Madrid 2009

Bourdieu, P. \& Passeron, J. (2010). Los herederos: los estudiantes y la cultura. Argentina: Edición Siglo XXI.

Brunner, J. (2008). Sociología crítica y políticas públicas (A propósito de algunos textos de Bourdieu). Seminario Internacional Vigencia y Urgencia del Pensamiento de Pierre Bourdieu. Santiago de Chile: Instituto de Investigación en Ciencias Sociales (ICSO) de la Universidad Diego Portales.

Brunner, J. (2013). Educación superior en tiempos de cambios: el reordenamiento institucional. Seminario internacional. Santiago de Chile: Aequalis \& Udla.

Calderón, J. (2003). Creencias y actuaciones de los profesores 
en procesos de enseñanza-aprendizaje de una cultura extranjera en el Cairo (Tesis para obtener el grado de magíster). Universidad de Barcelona.

Canales, A. \& De los Ríos, D. (2007). Factores Explicativos de la deserción Universitaria. Calidad de la Educación, (26), 173-201. Cárcamo, H. (2005). Hermenéutica y análisis cualitativo. Revista Cinta de Moebio, (23). Facultad de Ciencias Sociales de la Universidad de Chile.

Contreras, A. (2011). Una aproximación a la docencia universitaria desde las creencias docentes. Revista Perspectivas, (22). Santiago Chile: Universidad Católica Silva Henríquez.

De Garay, A. (2004). Integración de los jóvenes al sistema universitario. Prácticas académicas, sociales y de consumo cultural. Barcelona, España: Editorial Pomares.

Díaz, M. (2009). Igualdad de oportunidades en educación superior para los pueblos indígenas. Propuestas para la inclusión social. Revista ISSES, (3). Recuperado de http://www.isees. org/file. aspx?id=7534

Díaz-Romero, P. (2010). Universidades de calidad: universidades inclusivas. Santiago de Chile: Fundación Equitas.

Diccionario Larousse (2000). Recuperado el 23 de noviembre 2017 de: https://www.larousse.mx/app/diccionario-frances-espanol-2/

Dietz, G. (2007). Cultural Diversity: a guide to the debate. Zeitschrift für Erzieehungswissenschaft, 10(1), 7-30.

Dietz, G. (2012). Multiculturalismo, interculturalidad y diversidad en educación. Una aproximación antropológica. México: Fondo de Cultura Económica.

Espinoza, O. (2013) (Editor). Equidad e Inclusividad en la educación superior en los países andinos: los casos de Bolivia Chile, Colombia y Perú. Santiago de Chile: Ediciones Universidad UCINF. 
Espinoza, O. \& González, L. (2010). Políticas y estrategias de equidad e inclusión en educación superior en América Latina: experiencias y resultados. Revista_Isees, (7), 21-35. Santiago de Chile: Fundación Equitas.

Estermann, J. (2009) Hacia una interversidad de Saberes: Universidad e Interculturalidad. Disponible en www.ustabuca. edu.co/.../vustabmanga296148920140521104637

Ezcurra, A. (2007). Los estudiantes del nuevo ingreso: democratización y responsabilidad de las instituciones universitarias. Cuadernos de Pedagogía Universitaria. Buenos Aires, Argentina: Universidad Nacional de General Sarmiento.

Ezcurra, A. (2011). Igualdad en educación superior. Un desafío mundial (primera edición). Los Polvorines: Universidad Nacional de General Sarmiento-IEC/CONADU.

Fasciolli, A. (2011). Justicia social en clave de capacidades y reconocimiento. Revista Areté, 23(1), 53-57. Lima.

Fraser, N. (1996). Redistribución y reconocimiento: hacia una visión integrada de justicia del género. Revista Internacional de Filosofía Política, 8.

García, H. (2006). Educación Liberadora. En Pensamiento crítico Latinoamericano: Conceptos Fundamentales, (1), Santiago de Chile: Ediciones UCSH.

García J., Pulido, R. \& Montes, Á. (1997). La educación multicultural y el concepto de cultura. En Revista Iberoamericana de Educación, (13), Monográfico Educación Intercultural Bilingüe, OEI.

Giménez, C. \& Malgesini, G. (2000). Guía de conceptos sobre migraciones, racismo e interculturalidad. Madrid: Ediciones Catarata-Comunidad de Madrid.

Giménez, C. (2006). Pluralismo, multiculturalismo e interculturalidad: Propuesta de clarificación y apuntes educativos. Recuperado de http://red.pucp.edu.pe/ridei/wp-content/uploads/ biblioteca/100416.pdf 
Guzmán, M., Mardones, R. \& Cheuque, D. (2010). Si vas para Chile: Consideraciones, contextos, debates y desafíos del sistema educacional chileno ante la interculturalidad desde una mirada crítica. Diversia. Educación y Sociedad (3). CIDPA Valparaíso.

Hernández, F. (2007). La teoría crítica de Axel Honneth y la Sociología de la Educación. Foro Sociología de la Educación. Recuperado de http://www.uv.es/fjhernan/Textos/soc_educacio/FESBarcelona.pdf

Hervás, C. \& Martín, J. (1997). Evaluación de necesidades formativas, actitudes y creencias del profesorado de educación secundaria. Revista Electrónica Interuniversitaria de Formación del Profesorado. Disponible en http://w.aufop.com/aufop/ uploaded_files/articulos/1224239275.pdf

Honneth, A. (1996). Reconocimiento y obligaciones morales. Número 8 de la RJFP Traducción del alemán de Federico Maxínez. Disponible en http://e-spacio.uned.es/fez/eserv/bibliuned:filopoli-1996-8-6443431F-2BE8-F544-3A97-47F0DA074DF8/reconocimiento_obligaciones.pdf

Honneth, A. (2009). Crítica del Agravio Moral: Patologías de la sociedad contemporánea. Argentina: Fondo de Cultura Económica.

Honneth, A. (2010). Reconocimiento y menosprecio sobre la fundamentación normativa de una teoría social. Buenos Aires: Katz Editores.

Latorre, M. (2009). Prácticas pedagógicas en la encrucijada: argumentos, lógicas y razones de los actores involucrados. Revista Pensamiento Educativo, 44-45, 185-210.

López, J. (2012). Universidad e interculturalidad. En Tubino, F. y Mansilla, K. (Editores). Universidad e Interculturalidad. Desafíos para América Latina, 13-28. Perú: Pontificia Universidad Católica del Perú. Recuperado de http://red.pucp.edu.pe/ridei/ 
files/2012/05/Universidad_e_interculturalidad_para_web.pdf Lizón, M. (2000). Del efecto Simmel y la autopersuasión: la teoría cognitivista de las creencias de R. Boudon. Papers: Revista de Sociología, (62). Disponible en http://ddd.uab.cat/record/362 Marcelo, C. (1993). El primer año de enseñanza: análisis del proceso de socialización de profesores principiantes. Revista de Educación, 300, 225-277. ISSN 0034-8082.

Marchesi, A. (2000). Un sistema de indicadores de desigualdad educativa. Revista Iberoamericana de Educación, (23), 135-163.

Mato, D. (2007). Interculturalidad y educación superior: diversidad de contextos, actores, visiones y propuestas. Nómadas (Col.), (27), 62-73.

Mato, D. (2008). Diversidad Cultural e Interculturalidad en educación superior. UNESCO/IESALC.

OCDE \& Banco Mundial (2009). La educación superior en Chile. Revisión de políticas nacionales de educación. Recuperado de http://www7.uc.cl/webpuc/piloto/pdf/informe_OECD.pdf

Ortega \& Gasset, J. (1995). Ideas y creencias. Obras Completas, V, Alianza Editorial.

Pajares, M. F. (1992). Teachers. Beliefs and education research: Cleaning up a messy construct. Review of Educational Research, 63(3), 307-332.

Rama, C. (2011). La nueva reforma de la diversidad universitaria: de la diferenciación institucional a la diversidad educativa. Recuperado de http://es.slideshare.net/claudiorama/la-nueva-reforma-de-la-diversidad-universitaria

Ramírez, F. (2006). Educación intercultural: una respuesta a las sociedades multiculturales del siglo XXI. Portal de la educación intercultural. Recuperado de http://aulaintercultural.org/2004/12/08/educacion-intercultural-una-respuesta-a-las-sociedades-multiculturales-del-siglo-xxi/

Sabariego, M. (2009). La educación intercultural como factor de 
cambio social: modelos de intervención y acción educativa. En M. Esteban (coord.). El diálogo intercultural en España: un requisito de la educación y cultura de paz. Madrid: MEC-CIDE.

Salazar, M. (2009). Multiculturalidad e interculturalidad en el ámbito educativo: Experiencias de países latinoamericanos, Módulo 1 Módulo Enfoque teórico editado por IIDH.

Sampaio de Madureira, M. (2010). Introducción del libro. Crítica de agravio moral: patologías de la sociedad contemporanea de Axel Honneth. Buenos Aires: Fondo de Cultura Económica. Sartorello, S. (2009). Una perspectiva crítica sobre interculturalidad y educación intercultural bilingüe: El caso de la Unión de Maestros de la Nueva Educación para México (UNEM) y educadores independientes en Chiapas.

Schmelkes S. (2012). Multiculturalismo, educación intercultural y universidad. En F. Tubino y K. Mansilla (Editores). Universidad e Interculturalidad. Desafíos para América Latina, 55-86. Perú: Pontificia Universidad Católica del Perú. Recuperado de http://red.pucp.edu.pe/ridei/files/2012/05/Universidad_e_ interculturalidad_para_web.pdf

Sebastián, C. \& Scharager, J. (2007). Diversidad y educación superior. Algunas reflexiones iniciales. Calidad en la Educación, (26), 19-36.

Schmelkes, S. (2006). Las Universidades interculturales en México: ¿Una contribución a la equidad en educación superior? Recuperado de http://www.colombiaaprende.edu.co/html/mediateca/1607/articles-174704_archivo.pdf

Tarrow, N. (1992) "Lenguas, interculturalismo y derechos humanos", en Revista Perspectivas XXII (4). UNESCO, París, Francia, UNESCO, 489-509. En Multiculturalidad e interculturalidad en el ámbito educativo: experiencia de países latinoamericanos (2009). Instituto Interamericano de Derechos Humanos IIDH, p.18. 
Taylor, C. (2001). Multiculturalismo y política del reconocimiento. México: Fondo de Cultura Económica.

Tedesco, J. (2000). Educar en la sociedad del conocimiento. México: Fondo de Cultura Económica.

Tello, F. (2011). Las Esferas del Reconocimiento en la Teoría de Axel Honneth. Revista de Sociología, (25). Santiago de Chile: Universidad Alberto Hurtado.

Tubino, F. (2012). Formación universitaria para el desarrollo humano abierto a la diversidad. En F. Tubino y K. Mansilla, (1992). Universidad e Interculturalidad. Desafíos para América Latina. Perú: Pontificia Universidad Católica del Perú, 107124. Disponible en http://red.pucp.edu.pe/ridei/files/2012/05/ Universidad_e_interculturalidad_para_web.pdf

Tubino, F. (2005). La interculturalidad crítica como proyecto ético-político. Encuentro continental de educadores agustinos. Lima. Recuperado de https://oala.villanova.edu/congresos/ educacion/lima-ponen-02.html

UNESCO (2009). Conferencia Mundial sobre la Educación Superior (2009). La nueva dinámica de la educación superior y la investigación para el cambio social y el desarrollo. Sede UNESCO, 5-8 de julio de 2009, París, Francia.

Vain, P. (2000). La evaluación de la docencia universitaria: un problema complejo. Documentos de trabajo. Buenos Aires, Argentina: CONEAU.

Vera, L. (2006). La investigación cualitativa. Disponible en http:// www. ponce.inter.edu/cai/Comite-investigacion/investigacion-cualitativa.html

Walsh, C. (2005). La Interculturalidad en la Educación. Ministerio de Educación. Dirección Nacional de Educación Bilingüe Intercultural (DINEBI). Lima, Perú: Unicef y Gobierno de Perú. Weber, M. (1905). La ética Protestante y el Espirítu del Capitalismo. En: Ginen, S., De Espinoza, E. 
Weber, M. (1992). La política como vocación. En: Ginen, S., De Espinoza, E., Torres, C. (2004). Diccionario de Sociología, Alianza Edición Madrid.

Zaccagnini, M. (2001). Configuraciones del sujeto pedagógico contemporáneo. Rep. Argentina: Universidad Nacional de Mar del Plata. Disponible en http://www.fchst.unlpam.edu.ar/ iciels/171.pdf 